\title{
ENTRE O DEPARTAMENTO DE ESTADO, OS THINK TANKS E A USAID: A VISÃO ESTADUNIDENSE DAS ÁREAS NÃO- governadas Na AmÉRICA do Sul
}

\author{
Aline Pavan dos Santos ${ }^{1}$ e Luiza Mateo ${ }^{2}$
}

\begin{abstract}
Resumo
A natureza difusa das ameaças transnacionais e a falta de eficácia de alguns Estados, ao lidarem com problemas internos, aumentam exponencialmente 0 palco de manobra das potências. Neste aspecto se abordam as áreas não-governadas, que têm ganho relevância nas discussões sobre segurança internacional e impactaram em particular a política externa exercida pelos Estados Unidos no século XXI. A partir destes pressupostos propõe-se comentar, tendo como palco o continente Sul Americano, a definição utilizada para áreas não-governadas, o trato delas pelo Departamento de Estado dos EUA e pela USAID, sumarizar os locais de risco apontados por determinados centro de pensamento estratégico (Think Tanks) e comparar as localidades beneficiadas pela USAID, assim como também discutir a questão da baixa governabilidade regional.
\end{abstract}

Palavras-chave: Áreas não-governadas. Terrorismo. Estados Unidos. América do Sul.

\footnotetext{
${ }^{1}$ Mestranda em Relações Internacionais pelo Programa de Pós-Graduação San Tiago Dantas. UNESP, UNICAMP e PUC-SP, Brasil. apavan@ig.com.br

${ }^{2}$ Mestre em Relações Internacionais pelo Programa de Pós-Graduação San Tiago Dantas. UNESP, UNICAMP e PUC-SP, Brasil. luizamateo@ hotmail.com
} 


\section{BetWeEn The State DEPARTMENT, Think Tanks and USAID: THE AMERICAN VIEW OF UNGOVERNED AREAS IN SOUTH AMERICA \\ Abstract}

The diffuse nature of transnational threats and lack of effectiveness of some states in dealing with internal problems exponentially increase actions by world powers. This discussion covers the ungoverned areas, which have gained wide importance in discussions on international security, and have particularly impacted the foreign policy exercised by the U.S. in the twenty-first century. From these assumptions it is proposed to discuss, having the South American continent as the stage, the concept of ungoverned areas, their treatment by the U.S. State Department and USAID, summarize the locations at risk appointed by certain centers of strategic thinking (Think Tanks) and compare the locations benefited by USAID and the issue of low regional governance.

Keywords: Ungoverned areas. Terrorism. United States of America. South America.

\section{INTRODUÇÃO}

discussão em torno das áreas não-governadas estáligada às chamadas "novas
ameaças", definidas ao fim dos anos de 1980, que abarcam o terrorismo,
narcotráfico, as migrações ilegais e o crime organizado transnacional. Ao mesmo tempo, ela não se dissocia de discussões teóricas em torno de Estados Falidos, Estados Fracos e governança efetiva. Ambas as abordagens assumiram relevância nos estudos de segurança internacional e tiveram impacto particular na política externa dos Estados Unidos (EUA), seja por sua condição de potência no sistema internacional, ou pelo reconhecimento de que tais "espaços de baixa governança" são possíveis ameaças à estabilidade global e podem afetar diretamente o país, como ocorreu em 11 de setembro de 2001.

0 presente trabalho aborda a visão do Departamento de Estado norte americano (United States Department of State - USDS), de determinados centros de pensamento estratégico ${ }^{3}$ (think tanks) e da Agência de ajuda externa norteamericana (United States Agency for International Development - USAID),

\footnotetext{
${ }^{3}$ Foram consideradas as abordagens dos seguintes think tanks: Brookings Institution, Center for Strategic and International Studies (CSIS), Heritage Foundation, Hudson Institute e RAND Corporation. 0 critério de seleção incluiu a relevância que estes institutos dispensam à temática das áreas não-governadas e à proximidade deles com membros do governo estadunidense.
} 
sobretudo durante o Governo Barack Obama (2009-atual) no que tange às áreas não-governadas da América do Sul. A perspectiva do primeiro foi considerada por se tratar, dentro do governo dos Estados Unidos, do órgão formulador da política externa. Em seguida, os centros de pensamento estratégico foram incorporados ao estudo pela interlocução que operam junto aos tomadores de decisão do país em questão e, finalmente, o papel da USAID é elucidado como um meio operacional de se consolidar as propostas do USDS.

A partir de tais considerações, o trabalho se propõe a esclarecer a definição de áreas não-governadas, identificar os objetivos estratégicos do USDS para a América do Sul, sumarizar os locais de risco apontados pelos think tanks e mapear as áreas do continente que recebem auxílio da USAID. Doravante, parte-se para uma síntese das percepções estadunidenses no que tange à abordagem das áreas não-governadas no contexto sul-americano.

\section{DEFINIÇÕES PARA ÁREAS NÃO-GOVERNADAS}

A construção conceitual para "áreas não-governadas" está intimamente ligada ao desenvolvimento das percepções estadunidenses e ao léxico operado em seus órgãos burocráticos. Nesta esteira, destacamos dois marcos conceituais que contribuíram para a discussão sobre "zonas de governabilidade incompleta".

Um deles teve lugar com a gestão de Ronald Reagan (1981-1989), que cunhou o termo Estados párias (Rogue States) para indicar os países indispostos a seguir as normas da comunidade internacional, sobretudo em relação à posse de armas nucleares, abrangendo nações cujos regimes políticos manifestavam animosidade em relação aos Estados Unidos (NASSER, 2009). Contudo, o termo Rogue States pouco auxiliava na compreensão dos crescentes desafios à segurança, menos ligados à indisciplina de alguns Estados que à incapacidade de outros para manter o controle efetivo sobre porções significativas do território nacional.

Para suprir esta lacuna, o governo americano passou a adotar a ideia de Estado falido, que apareceu nos documentos a partir de 1998, durante o governo Clinton. Entretanto, somente após os atentados de 11/09 o tema ganhou evidência, aparecendo já na Estratégia de Segurança Nacional de 2002 “[...] Estados fracos, como o Afeganistão, podem representar grande perigo aos nossos interesses nacionais tanto quanto Estados fortes" (NATIONAL SECURITY STRATEGY - NSS, 2002, p. 4, tradução nossa). 
Foi entre 2007 e 2008 que o emprego da expressão "áreas não-governadas" primeiro apareceu nos documentos do Departamento de Defesa norte-americano (LAMB, 2008). Tal concepção fornece ferramentas para análise de novas dinâmicas, tais como os atores transnacionais, uso de novas mídias (ex. propaganda do islamismo radical) e exploração dos buracos virtuais (ex. lavagem de dinheiro), fronteiras borradas por identidades desterritorializadas (ex. etnias na África e tribos árabes), conflitos civis e fluxos de refugiados, e perigos vindos de áreas suburbanas (ex. os banlieus de Paris ou favelas do Rio de Janeiro).

No tocante aos espaços físicos, a expressão áreas não-governadas denota, portanto, a incapacidade de controle, pela autoridade estatal, do território circunscrito por suas fronteiras. Refere-se aos locais em que há debilidade total do poder governamental ou uma intermitência no exercício de soberania pelo poder formal (zonas de baixa governabilidade). Esta situação pode ser encontrada em Estados que, a despeito de sua robustez econômica e legitimidade política, não estão aptos a exercer autoridade sobre todo o território que lhes pertence por ineficiência do seu aparato burocrático e logístico (GATES, 2010; LAMB, 2008; MENKHAUS, 2007; RABASA et al., 2007).

Menkhaus (2007) assinala, ainda, que estes espaços são caracterizados por emergências humanitárias crônicas e deslocamentos migratórios generalizados e pela presença de operações de paz e assistência humanitária internacional. Como consequência de forças distintas administrando um mesmo complexo, surgem arranjos de autoridade híbridos, tais como a coexistência de atores tradicionais, civis ou religiosos, empreendedores transnacionais, forças de defesa privadas e agentes internacionais. Sistemas desta natureza costumam ser frágeis, fluidos e geralmente avessos à democracia, mas proporcionam um espectro de previsibilidade às comunidades locais.

Segundo alguns críticos, a existência de espaços não-governados não é um fenômeno novo e mesmo o emprego do conceito seria equivocado, pois traz uma concepção "estadocêntrica" e universalista, desenvolvida por governos e organizações internacionais no pós Guerra Fria: "Na realidade, muitos dos chamados espaços não-governados são simplesmente governados de modo diferente." (CLUNAN; TRINKUNAS, 2008, p. 5, tradução nossa). Ou seja, a questão das áreas não-governadas refletiria tão somente a corrosão do projeto ocidental para enxertar um modelo específico de organização político-territorial a partir de instrumentos como: ideologia universalista liberal, incorporação à economia 
globalizada e apoio diplomático-militar às elites no poder. Neste esquema, "boa governança" e "soberania efetiva" são vistas como o único remédio para desvios ao Estado Constitucional e para males locais como subdesenvolvimento, corrupção, difusão de atividades ilícitas ou insurgência social.

Para os EUA, a ameaça dos territórios não-governados reside no fato de que o vácuo de poder deixado pelo Estado acarreta a perda do monopólio do uso da força e, com isso, favorece a emergência de poderes para-estatais com acesso a armamentos, ao tráfico e ao crime. Em última instância, esses fatores se somam a condições degradantes de sobrevivência das populações locais que se afiliam a grupos capazes de suprir suas necessidades básicas. Com isso, estas populações passam a ser recrutáveis para ações terroristas ou participantes na produção de entorpecentes. Em outras palavras, áreas não-governadas constituem potenciais santuários terroristas que, segundo Lamb (2008), podem existir em áreas remotas, espaços urbanos, ambientes marítimos ou redes de comunicação em que atores ilícitos conseguem organizar, planejar, angariar fundos, recrutar, treinar e operar sem que um órgão regulador legítimo os impeça.

Dada a variedade de situações existentes nessas condições, o projeto realizado pela RAND Corporation (RABASA et al., 2007), desenvolveu uma metodologia para avaliar os graus de ingovernabilidade territorial. Para tanto, propôs indicadores relativos ao vácuo de penetração estatal, demonstrado pela ausência de instituições e infraestrutura física, concomitante predominância da corrupção e da economia informal, bem como resistência social e cultural aos EUA. Os indicadores pretendem avaliar também o nível de perda do monopólio da força pelos Estados ao considerar o acesso da população às armas e a existência de redes criminosas, bem como ponderam o nível de controle sobre as fronteiras e 0 grau de interferência externa sobre as regiões.

Terminologias usadas tais como Estados pária, Estados Falidos, áreas não-governadas e santuários terroristas, possuem, portanto, uma finalidade bastante prática: identificar as fontes de risco e auxiliar no combate às ameaças que se delineiam frente ao palco de atuação estadunidense. Desta perspectiva, a segurança e a defesa da região sul-americana são singulares: inexistem guerras formais, porém, culminam problemas relativos à fragilidade do império da lei em regiões de fronteiras e pontuais áreas urbanas, como o tráfico de drogas e o alto grau de violência social. 


\section{As ÁREAS NÃO-GOVERNADAS NA GRANDE ESTRATÉGIA NORTE-AMERICANA}

A Estratégia de Segurança Nacional (National Security Strategy - NSS) é um documento elaborado periodicamente pelo Executivo norte-americano a fim de enunciar as principais preocupações de segurança nacional e como 0 governo pretende lidar com elas. Em 2010, o presidente Barack Obama publicou sua primeira NSS que, já na introdução, classifica os Estados falidos como fonte global de instabilidade e ameaça. No tocante ao combate à Al Qaeda, insiste na sua neutralização através da promoção de oportunidades e esperança em países vulneráveis, previnindo o surgimento de possíveis santuários terroristas.

Nela, a luta contra o terrorismo foi vinculada à superação do déficit político, econômico e social, provendo necessidades básicas para Estados "em risco" com atuação governamental enfraquecida pois "governos incapazes de atender as necessidades básicas de seus cidadãos e cumprir suas responsabilidades de prover segurança dentro da fronteira, podem acarretar consequencias globais e oferecer ameaça direta ao povo americano." (NSS, 2010, p. 26, tradução nossa).

Há uma ênfase no fortalecimento das capacidades dos Estados em questões de segurança, bem-estar social e recuperação pós-desastre ambiental ou pós-conflito: "A boa governança é o único caminho para garantir a paz e a segurança douradora." (NSS, 2010, p. 26, tradução nossa). 0 bom funcionamento do sistema internacional dependeria, assim, da recuperação de Estados Fracos e suas respectivas instituições, lideranças políticas e sociedade civil. A própria segurança americana dependeria do auxilio às democracias novas e frágeis, na distribuição de bens sociais aos seus cidadãos. 0 documento de 2010 dispõe, em diversos momentos, a relação entre democracia, direitos humanos, prosperidade e segurança, convocando os EUA a trabalhar em conjunto com as populações, comunidades e governos promovendo a dignidade através de necessidades básicas como acesso a comida, àgua potável e medicamentos.

As principais linhas temáticas e programáticas do Departamento de Estado e da USAID estão condensadas no Plano Estratégico (Strategic Plan), que é um documento lançado periodicamente a fim de atualizar os rumos da política externa em relação aos objetivos delimitados na NSS. No governo Obama, vigoram as diretrizes estratégicas da Diplomacia Transformacional (Transformational Diplomacy 2007-2012), cujo objetivo repousa na associação entre liberdade, 
segurança e prosperidade, com a delimitação de sete objetivos a serem perseguidos na sua política externa dos EUA (USDS; USAID, 2007, p. 9-38):

1. Atingir a paz e a segurança

2. Governar justa e democraticamente

3. Investir nas pessoas

4. Promover crescimento econômico e prosperidade

5. Prover auxílio humanitário

6. Promover o entendimento internacional

7. Alinhamento consular e gerenciamento de capacidades

Pudemos notar, no mesmo documento, que os objetivos ligados à paz e à segurança internacional estão intimamente ligados à erradicação do terrorismo e do crime transnacional. Além destes, aparecem complementarmente a promoção de controle das armas convencionais e de destruição em massa, articulação de mecanismos para a promoção da cooperação em segurança, minimizando a ocorrência de conflitos e assegurando a segurança doméstica norte-americana.

Nota-se, destarte, que os temas apresentados pelo Plano Estratégico perpassam a necessidade de estabilização das áreas não-governadas através de um conjunto de ações possíveis pela política externa americana. Como afirma Miko (2005), erradicar o terrorismo envolve o emprego de forças militares e sanções, no entanto, não fica isento da utilização de instrumentos como a diplomacia, a assistência econômica e outros programas sociais capazes de arraigar a governança.

Mesmo sem explicitar a aplicação do conceito área não-governada, o Plano Estratégico em questão afirma que "os mais intratáveis santuários terroristas existem em regiões fronteiriças ou sem governança. Precisamos desenvolver meios para retirar estes refúgios de terroristas" (USDS; USAID, 2007, p. 12, tradução nossa). No que se refere ao crime transnacional, os EUA se posicionam no intuito de manter a luta contra a produção, o transporte e a venda de entorpecentes assim como apontam que este assunto está diretamente ligado ao continente americano (USDS; USAID, 2007, p. 15).

Na sequência do Plano Estratégico são elucidados os seguintes fatores externos capazes de impactar na obtenção dos objetivos políticos e programas estadunidenses de promoção da segurança internacional tais como (USDS; USAID, 2007, p. 17): 
- Instabilidade política, social ou econômica;

- $\quad$ Corrupção endêmica;

- Violentas manifestações anti-EUA;

- $\quad$ Latentes tensões étnicas e religiosas internas ou entre as nações;

- Controle inexistente ou inadequado das fronteiras e do território sobre jurisdição soberana;

- Instituições inadequadas ou inexistentes para aplicação da lei.

No tocante ao Hemisfério Ocidental, e consequentemente à América do Sul, predomina no Plano a percepção de que as ameaças não são oriundas exclusivamente de inimigos políticos, mas, antes, de vulnerabilidades sociais, econômicas e governamentais. Com isso, a proposta para a região fica circunscrita ao fortalecimento dos regimes democráticos e da abertura de mercados para alavancar o desenvolvimento econômico. Para tanto, vislumbra-se a possibilidade de continuar operando multilateralmente como na Organização dos Estados Americanos (OEA) para combater a pobreza, a desigualdade social e a marginalização política.

A promoção da prosperidade está vinculada, para os países da região, ao financiamento de programas capazes de fortalecer os produtores locais, em especial no setor agrícola, visto como essencial para o desenvolvimento econômico e também como meio de combate à produção e ao tráfico de entorpecentes. Os investimentos também preveem, complementarmente, apoio ao setor educacional, à saúde e ao saneamento básico.

Ainda na estrutura do USDS há uma área responsável pela análise do terrorismo ao redor do mundo. Desde 2004, o Country Reports on Terrorism é publicado com o intuito de demonstrar o envolvimento de cada país com crimes desta natureza. 0 relatório apresenta a classificação, sob a leitura específica dos EUA, de Estados considerados patrocinadores do terrorismo e de organizações demarcadas como terroristas.

Em termos gerais, o relatório de 2009 indica que o Hemisfério Ocidental possui pouca relação com as atividades terroristas transnacionais, sendo o mais preocupante o fato de integrantes do Hezbollah e do HAMAS estar levantando fundos com práticas ilícitas na Tríplice Fronteira (Argentina, Brasil e Paraguai), ainda que não haja confirmação da presença operacional dos grupos na região. Ressalta-se ainda o fato de que nenhum dos Estados sul-americanos é classificado 
como patrocinador do terrorismo, apesar da Venezuela ser considerada um santuário (USDS, 2010, p. 163-165). Das 44 organizações terroristas mapeadas, apenas cinco pertencem à região: Movimento Revolucionário Tupac Amaru (MRTA) boliviano, Sendero Luminoso no Peru, Forças Armadas Revolucionárias da Colômbia (FARC), Auto-defesas Unidas da Colômbia (AUC) e Exército de Libertação Nacional (ELN) também colombiano (USDS, 2010, p. 235-287).

A Argentina e o Brasil são vistos como extremamente colaborativos no combate ao terrorismo e livres de movimentos capazes de ameaçar os interesses estadunidenses. Países como Chile, Peru e Paraguai preocupam o USDS, pois seus esforços têm sido pouco frutíferos na contenção de disputas em terras indígenas e na criação e aplicação efetiva de legislações capazes de diminuírem a corrupção e a criminalidade. Já a Bolívia aparece como um dos maiores cooperadores, enquanto a Venezuela se classifica entre os que não colaboram (USDS, 2010, p. 165-190).

Outro ponto que ameniza as preocupações estadunidenses na região diz respeito à inexistência de armas de destruição em massa. Desde a década de 1990, todos os países da América do Sul são signatários do Tratado de Não Proliferação (TNP) e os que buscam desenvolver conhecimento sobre tecnologia nuclear o fazem dentro dos termos desse Tratado, portanto, acredita-se que para fins pacíficos.

Como nem todas as áreas não-governadas colocam o mesmo risco para os Estados Unidos, o orçamento para prevenir e tratar os problemas dessa natureza é endereçado de acordo com a relevância que a ação terá no esforço de combate ao crime transnacional e ao terrorismo. Especificamente, o orçamento previsto pelo Executivo norte-americano para as atividades de política externa em $2011^{4}$ somou US\$52,8 bilhões, a serem distribuídos em projetos do USDS (US\$16,4 bilhões) e da USAID (US\$36,4 bilhões).

\section{A VISÃO DOS THINK TANKS NOS MARCOS DA SEGURANÇA SUL-AMERICANA}

Enquanto o Departamento de Estado apresenta uma proposta sucinta para o Hemisfério Ocidental e trata as áreas não-governadas implicitamente nos documentos oficiais, os centros de pensamento estratégico se encarregam de

\footnotetext{
${ }^{4} 0$ orçamento de 2011 teve um aumento de 2,8\% (US\$4,9 bilhões) em relação ao ano fiscal de 2010, dos quais US $\$ 3,6$ bilhões estão comprometidos com os frontline states: Afeganistão, Paquistão e Iraque. 0 Internacional Affairs Budget compreende apenas $1.4 \%$ do orçamento total norteamericano, representando apenas um sexto $(1,7 \%)$ do valor reservado à segurança nacional ou 7,4\% do orçamento de defesa, que em 2011 foi calculado em US\$708 bilhões (CLINTON, 2010, p. 2).
} 
desenvolver estudos mais detalhados e explícitos que, em última instância, irão influenciar o direcionamento dos recursos governamentais dos EUA.

Nota-se uma convergência entre os think tanks pesquisados e o USDS quanto à identificação da natureza difusa das ameaças que desafiam os EUA. Todos concordam que as questões de segurança mais latentes estão na África e no Oriente Médio e que o caso sul-americano preocupa, principalmente, pela produção de coca, pelos índices de violência e pela debilidade das instituições democráticas e desajustes sociais.

Nesta linha, as pesquisas do Centro de Estudos Estratégicos e Internacionais (Center for Strategic and International Studies - CSIS) voltam seu foco para os Estados Falidos e privilegiam Irã, Iraque e Paquistão. Na América do Sul, apenas a Colômbia recebe atenção especial do CSIS, porém, o foco está em uma delimitação histórica e avaliativa da implementação e resultados do Plano Colômbia (DESHAZO; FORMAN; MCLEAN, 2009).

A RAND Corporation vai além, ao definir conceitualmente a expressão áreas não-governadas, criar uma metodologia de análise e incluir em seus estudos de caso a fronteira entre Colômbia e Venezuela. Segundo este think tank, a fronteira é utilizada como refúgio das guerrilhas colombianas e como rota para o tráfico de drogas e armas. Além disso, preocupam aos analistas o subdesenvolvimento da região e sua diversidade étnica, já que ali residem em torno de 80 grupos indígenas distintos (RABASA et al., 2007, p. 243-276).

A Brookings Institution e o Hudson Institute se debruçaram sobre 0 crescimento urbano desordenado e as implicações que este fator pode ter para a segurança pública, a degradação ambiental e a proliferação de doenças. Especificamente Brainard (2008), do Brooking Instituition, identifica que a expansão da ajuda internacional é essencial para dar continuidade ao desenvolvimento sul-americano e afirma inclusive que este é um meio de disseminar valores estadunidenses e fortalecer a democracia.

Concomitantemente, no Hudson Institute (DAREMBLUM, 2009), os pesquisadores identificam como fatores de risco na região a Venezuela governada por Hugo Chávez e a situação política nas favelas de São Paulo, Rio de Janeiro, Buenos Aires e Caracas. Sobre esta falta de governança, Cirino (2007, p. 1) avalia que:

Um olhar atento para São Paulo, Rio de Janeiro, Buenos Aires ou Caracas para mencionar apenas quarto exemplos - nos mostram que vagarosamente, 
quase imperceptivelmente, a "sociedade" nestes países passa a aceitar formas de "pequenas anarquias" [...]. Os limites entre o legal e 0 ilegal se tornam gradualmente borrados, e uma retórica de justificativa esta disponível para todas as atividades criminosas, mesmo as mais alarmantes (tradução nossa).

Para finalizar a composição do leque de ameaças regionais, a Heritage Foundation explora a realidade da região andina. Eiras et al. (2002) identificam que a instabilidade política e as dificuldades econômicas fazem com que a pobreza se perpetue nesses países. A estes fatores se agregam o cultivo de coca e a manutenção do tráfico de narcóticos na Bolívia, Colômbia e Peru. Com isto, os estudos sugerem que a política externa dos EUA deve encorajar estes países a privatizarem empresas estatais, liberalizarem mercados, controlar a inflação e estabelecer leis fortes e aplicáveis. No plano bilateral, apóiam a manutenção da ajuda à Colômbia na luta contra as guerrilhas, propõem auxílio a Equador, Peru e Bolívia para eliminar a corrupção e preservar as instituições democráticas.

No estudo conduzido por Johnson (2005), a negligência colombiana quanto à imposição de autoridade estatal sobre as comunidades rurais e a zona de fronteiras foi o que propiciou a expansão das FARC. Com isso, o alerta é para que a mesma situação não se estenda às favelas brasileiras e à Tríplice Fronteira, já que se nota 0 aumento de ações ilícitas cometidas nestes locais.

Para Walser (2008), a produção e o tráfico de narcóticos na América do Sul deixaram de ser um problema circunscrito à Colômbia e estão se expandindo rapidamente para 0 Equador e a Venezuela. 0 autor também ressalta 0 aumento da criminalidade na região e sugere que os EUA pressionem os membros da OEA a reconhecer as FARC e o grupo brasileiro PCC (Primeiro Comando da Capital) como organizações terroristas, para que sejam aplicadas as sanções cabíveis. Já para lidar com as manifestações antiamericanas, a estratégia identificada é o emprego diplomático para neutralizar os discursos de Hugo Chávez e Evo Morales. No geral, os think tanks reiteram as preocupações do Departamento de Estado, apontam os locais que merecem maior atenção da política externa norte-americana e propõem meios de conduta que extrapolam as ações militares.

\section{O PAPEL DA USAID NA BUSCA PELA GOVERNANÇA}

Com base na ideia de que a assistência externa e no fomento do desenvolvimento são um compromisso e, ao mesmo tempo, pilares da estratégia de 
segurança nacional estadunidense, a USAID aparece como ferramenta no auxílio ao desenvolvimento de nações pacíficas, estáveis e economicamente consolidadas.

A intenção primária da Agência é a de reconstruir os laços entre o Estado e a sociedade civil. Segundo Gleason et al. (2011), este processo resulta na obtenção da legitimidade governamental que é o componente principal de uma construção estatal efetiva e advém da capacidade do governo cumprir suas funções políticas, econômicas, de segurança e de bem estar social. Como coloca a diretora de assistência internacional Henrietta Fore (USDS; USAID, 2007, p. 6) o objetivo final da assistência é o de que as nações favorecidas possam sustentar projetos e avançar de modo autônomo.

Para a América Latina e o Caribe, as metas estabelecidas pela USAID permeiam quatro grandes eixos: amparar os objetivos da Cúpula das Américas 5 , promover oportunidades sociais e econômicas, garantir a segurança dos cidadãos e consolidar a governança efetiva (USAID, 2011a). Especificamente na América do Sul, recebem atualmente suporte da USAID (2011b): Bolívia, Brasil, Colômbia, Equador, Guiana, Paraguai e Peru. Os programas para cada um dos países mencionados estão sintetizados no quadro abaixo.

\section{Quadro 1 - Programas da USAID para a América do Sul (2010 / 2011)}

\begin{tabular}{|c|l|l|l|}
\hline & \multicolumn{1}{|c|}{ Programas } & \multicolumn{1}{|c|}{ Região geográfica } & \multicolumn{1}{|c|}{$\begin{array}{l}\text { Investimentos 2010 } \\
\text { (em milhões de US\$) }\end{array}$} \\
\hline Bolívia & $\begin{array}{l}\text { Desenvolvimento } \\
\text { Integral } \\
\text { Saúde } \\
\text { Crescimento sustentável } \\
\text { e Meio Ambiente }\end{array}$ & $\begin{array}{l}\text { Projetos nos 09 estados } \\
\text { bolivianos }\end{array}$ & $\begin{array}{l}\text { US\$ 52.158 } \\
\text { Divididos em cerca de } \\
\text { 30\% para cada um dos } \\
\text { programas. }\end{array}$ \\
\hline Brasil & $\begin{array}{l}\text { Meio Ambiente } \\
\text { Saúde } \\
\text { Energia } \\
\text { Empregabilidade }\end{array}$ & $\begin{array}{l}\text { Distribuição dos projetos: } \\
\text { 10 Norte } \\
\text { 07 Nordeste } \\
\text { 09 Sudeste } \\
\text { 04 Centro-0este } \\
\text { 03 Sul }\end{array}$ & $\begin{array}{l}\text { Meio Ambiente: } 59 \% \\
\text { Saúde: } 26 \%\end{array}$ \\
& & \\
\hline
\end{tabular}

\footnotetext{
${ }^{5}$ A Cúpula das Américas data de 1994 e prevê a reunião dos Estados Americanos (exceto Cuba) para promover a democracia, o livre comércio e o desenvolvimento sustentável.
} 


\begin{tabular}{|c|c|c|c|}
\hline Colômbia & $\begin{array}{l}\text { Meio Ambiente } \\
\text { Democracia e Direitos } \\
\text { Humanos } \\
\text { Populações vulneráveis } \\
\text { Segurança e } \\
\text { produtividade }\end{array}$ & & $\begin{array}{l}\text { USD 227, } 236 \\
\text { Está entre os } 20 \text { países } \\
\text { que mais receberam } \\
\text { recursos em } 2010\end{array}$ \\
\hline Equador & $\begin{array}{l}\text { Desenvolvimento } \\
\text { alternativo } \\
\text { Democracia } \\
\text { Crescimento Econômico } \\
\text { Meio Ambiente } \\
\text { Pessoas com deficiência } \\
\text { Tráfico de pessoas }\end{array}$ & $\begin{array}{l}\text { Principalmente nas } \\
\text { fronteiras norte e sul }\end{array}$ & US\$ $26.000 *$ \\
\hline Guiana & $\begin{array}{l}\text { Democracia } \\
\text { Crescimento econômico } \\
\text { Saúde } \\
\text { Threshold Program }\end{array}$ & US $\$ 24.000 * *$ & \\
\hline Paraguai & $\begin{array}{l}\text { Democracia } \\
\text { Meio Ambiente } \\
\text { Saúde } \\
\text { Crescimento Econômico } \\
\text { Threshold Program } \\
\text { Iniciativa da Fronteira } \\
\text { Norte }\end{array}$ & $\begin{array}{l}\text { Concentrados na região } \\
\text { Sul }\end{array}$ & US\$ $18.000^{*}$ \\
\hline Peru & $\begin{array}{l}\text { Democracia } \\
\text { Crescimento econômico } \\
\text { Saúde } \\
\text { Meio ambiente } \\
\text { Educação } \\
\text { Desenvolvimento } \\
\text { sustentável }\end{array}$ & $\begin{array}{l}07 \text { estados atendidos } \\
\text { pela proposta de } \\
\text { desenvolvimento } \\
\text { integrado } \\
03 \text { estados atendidos pelo } \\
\text { programa de fronteiras }\end{array}$ & $\begin{array}{l}\text { USD } 87.603 \\
\begin{array}{l}\text { Desenvolvimento } \\
\text { sustentável: } 36 \%\end{array} \\
\begin{array}{l}\text { Meio ambiente, } \\
\text { democracia e saúde: } 14 \%\end{array}\end{array}$ \\
\hline
\end{tabular}

Fonte: Desenvolvido com base dos dados dos sites das: USAID Bolivia; USAID Brasil; USAID Bogotá/ Colombia; USAID Ecuador; USAID. Latin America and the Caribbean; USAID Peru; USAID Policy, 2011.

* valor aproximado com base em 2009.

** valor aproximado com base em 2008.

Em uma análise comparativa, nota-se que estes programas estão dirigidos a temas recorrentes como saúde, meio ambiente, fortalecimento democrático e crescimento econômico. As atividades desempenhadas por tais programas 
vão desde o combate à tuberculose e à AIDS, até a promoção de campanhas de vacinação e o fornecimento de água potável e saneamento básico.

Ressaltam-se ainda fundos destinados a ampliações na infraestrutura dos países atendidos, como a construção de pontes e rodovias. Sobretudo nos Estados Andinos, preponderam projetos voltados à substituição produtiva como meio de mitigar o cultivo de coca, e, nestes casos, a Agência fornece desde treinamentos para o cultivo de outros produtos até a mediação com compradores no mercado internacional.

Outra iniciativa, denominada Threshold Program, compreende 0 fortalecimento das auditorias governamentais, combate à corrupção e proteção de direitos, por exemplo, à propriedade intelectual. Além da USAID, esta iniciativa conta com o financiamento do Millennium Challenge Corporation (MCC) que é responsável pelo acompanhamento de indicadores sobre governança, abertura econômica e investimento na população. Trata-se, portanto de um meio para influenciar os governantes dos países em desenvolvimento e conscientizar as populações sobre as vantagens de estabelecer um governo democrático segundo os padrões estadunidenses.

Destaca-se, contudo, que os programas levados a cabo pela USAID possuem limitações de prazo e abrangência. Em outras palavras, não são capazes de dar conta da totalidade da população necessitada e ficam sujeitas a aprovações orçamentárias anuais no congresso dos Estados Unidos.

\section{CONSIDERAÇõES FINAIS}

Cabe enfatizar que a abordagem das áreas não-governadas é hoje central para os estudos de segurança e defesa já que a ela remete-se uma série de ameaças à estabilidade internacional, além de ser comumente atrelada a correlatos como "boa governança" e fragilidade ou falência estatal. Ressaltam-se ainda as implicações práticas de tal conceito na agenda política dos EUA que concomitantemente lhes impõe desafios e lhes abre espaço de manobra para interferir em outros Estados.

$\mathrm{Na}$ estratégia estadunidense permanece o intuito de promover Estados democráticos, ou seja, com o poder judiciário estabelecido e eleições periódicas, com economia de mercado e capazes de responder às necessidades de sua população. Com isso, aparece nos documentos estratégicos uma preocupação de como lidar 
regiões remotas, fronteiriças ou de complexos urbanos não controlados por uma autoridade estatal conforme sugerem os padrões da potência norte-americana.

Se por um lado nos documentos do USDS e USAID o conceito de áreas nãogovernadas e o debate sobre governança efetiva são vetores implícitos de referência na formulação política, de outro lado as proposições elaboradas pelos think tanks são mais assertivas e determinados locais são pontualmente qualificados como não-governados. Vale ressaltar, neste sentido, que as pesquisas conduzidas pelos centros de pensamento estratégicos, apesar de não terem o peso formal da rubrica governamental, são constantemente levada em consideração para a tomada de decisões políticas.

Especificamente na América do Sul, a preocupação norte-americana é fortalecer o papel do Estado, em sua capacidade institucional e enquanto provedor de infraestrutura socioeconômica. Em tal quadro, a USAID patrocina programas assistencialistas às populações e projetos de apoio aos governos para suprir as fragilidades vivenciadas pela região, sendo explícita a relação entre as localidades beneficiadas e a questão da baixa governabilidade. Como consequências diretas se apresentam uma crescente influência dos EUA em assuntos internos dos países sulamericanos e a utilização da ajuda internacional como ferramenta diplomática capaz de atender parte dos objetivos estratégicos estadunidenses.

\section{REFERÊNCIAS}

CIRINO, Julio A. Urban areas out of control: looking at Buenos Aires and Rio de Janeiro. Buenos Aires: 2007. Disponível em: <http://www.hudson.org/files/ documents/julio cirino_urban_areas.pdf>. Acesso em: 15 abr. 2011.

CLINTON, Hillary R. Foreign Policy Priorities: the FY2011 International Affairs Budget. Washington, DC, fev. 2010. Disponível em: <http://www.state.gov/ secretary/rm/2010/02/137256.htm >. Acesso em: 18 fev. 2011.

CLUNAN, Anne L.; TRINKUNAS, Harold. Ungoverned spaces? Alternatives to state authority in an era of softened sovereignty. In: INTERNATIONAL STUDIES ASSOCIATION, 48., 2008. Meeting .. . São Francisco, 2008.

DAREMBLUM, Jaime. Populism, islamism and "indigenismo" vs. democracy in Latin America. 2009. Disponível em: < http://www.hudson.org/files/documents/ PopulismIndigenismo_Transcript.pdf > . Acesso em: 12 fev. 2011. 
DESHAZO, Peter; FORMAN, Johanna Mendelson; MCLEAN, Phillip. Countering threats to security and stability in a failing state: lessons from Colombia. Washington: CSIS, 2009. Disponível em: <http://csis.org/publication/counteringthreats-security-and-stability-failing-state>. Acesso em: 8 mar. 2011.

EIRAS, Ana et al. Time to change U.S. strategy for the andean region. 2002. Disponível em: <http:/www.heritage.org/Research/Reports/2002/02/Time-toChange-US-Strategy-for-the-Andean-Region>. Acesso em: 15 fev. 2011.

GATES, Robert M. Helping others defend themselves. Foreing Affairs, v. 89, n. 3, may/ june 2010.

GLEASON, Megan et al. Statebuilding in situations of fragility and conflict: relevance for US policies and programs. Washignton: USAID, 2011. Disponível em: <http://csis.org/files/publication/110218_Statebuilding_in_Situations_ Fragility_Conflict.pdf>. Acesso em: 25 jan. 2011.

JOHNSON, Stephen. Latin America's security puzzle. 2005. Disponível em: $<$ http://www.heritage.org/Research/Testimony/Latin-Americas-Security-Puzzle>. Acesso em: 15 fev. 2011.

LAMB, Robert D. Ungoverned areas and the threats from safe havens. 2008. Disponível em: < http://www.cissm.umd.edu/papers/files/ugash_report_final.pdf >. Acesso em: 11 nov. 2010.

MENKHAUS, Ken. Terrorist activities in ungoverned spaces: evidence and observations from the horn of Africa. 2007. Disponivel em: <http://www. thebrenthurstfoundation.org/Files/terror_talks/Terrorist\%20Activities\%20in\%20 Ungoverned\%20Spaces.pdf >. Acesso em: 9 set. 2010.

MIKO, Francis T. Removing terrorist sanctuaries: the 9/11 commission, recommendations and U.S. policy. 2005. Disponível em: <http://www.fas.org/sgp/ crs/terror/RL32518.pdf>. Acesso em: 24 maio 2011.

NASSER, Reginaldo Mattar. Os Estados falidos: novas ameaças e novas oportunidades. In: NASSER, Reginaldo M. Os conflitos internacionais em múltiplas dimensões. São Paulo: Ed. UNESP, 2009. p. 115-124.

NATIONAL SECURITY STRATEGY - NSS. The national security strategy: of the united states of America. Washington DC: The White House, 2002.

The national security strategy: of the united states of America. Washington DC: The White House, 2010. 
RABASA, Angel et al. Ungoverned territories: understanding and reducing terrorism risks. 2007. Disponível em: <http://www.rand.org/pubs/monographs/2007/ RAND_MG561.pdf>. Acesso em: 9 set 2010.

USAID. Bolivia. Perfil de País. Disponível em: < http://bolivia.usaid.gov/perfil. php>. Acesso em: 20 maio 2011.

. Brasil. Perfil de País. Disponível em: <http://brazil.usaid.gov/pt/ node/37>. Acesso em: 20 maio 2011.

. Ecuador. Sectores. Disponível em: <http://ecuador.usaid.gov/index. php?option $=$ com_content\&view $=$ section \&id $=7 \&$ Itemid $=54 \&$ lang $=e s>$. Acesso em: 20 maio 2011.

Embassy Sections. Bogotá. Colombia. United States Agency for International Development. Disponível em: < http://bogota.usembassy.gov/ usaid.html>. Acesso em: 20 maio 2011.

Latin America and caribbean. Disponível em: <http://www.usaid.gov/ locations/latin_america_caribbean/>. Acesso em: 10 maio 2011a.

Latin America and the Caribbean. Guyana: Overview. Disponível em: $<$ http://www.usaid.gov/locations/latin_america_caribbean/country/guyana/ index.html>. Acesso em: 20 maio 2011.

.Peru. Strategy: south America regional programs. Disponivel em: $<$ http://www.usaid.gov/pe/regionalprograms.htm>. Acesso em 20 mai. 2011.

. Policy. Where does USAID's Money Go? Disponível em: <http://www. usaid.gov/policy/budget/money/>. Acesso em: 20 maio 2011.

. USAID regions and countries. Disponível em <http://www.usaid.gov/ locations/>. Acesso em 10 mai. 2011b.

USDS. Country reports on terrorism 2009. Washington, 2010. Disponível em: $<$ http://www.state.gov/documents/organization/141114.pdf>. Acesso em: 24 maio 2011.

USDS; USAID. Strategic plan: transformational diplomacy. Washington, 2007. Disponível em: <http://www.usaid.gov/policy/coordination/stratplan_fy07-12.pdf >. Acesso em: 24 maio 2011.

WALSER, Ray. Terrorism, insurgency, and drugs still threaten america's southern flank. 2008. Disponível em <http://www.heritage.org/Research/ Reports/2008/06/Terrorism-Insurgency-and-Drugs-Still-Threaten-AmericasSouthern-Flank>. Acesso em: 15 fev. 2011. 